\title{
What should governments be doing to prevent diabetes throughout the life course?
}

\author{
Patrick Timpel $^{1}$ • Lorenz Harst ${ }^{2}$ • Doreen Reifegerste ${ }^{3}$ - Susann Weihrauch-Blüher ${ }^{4}$ • Peter E. H. Schwarz ${ }^{1,5,6}$
}

Received: 28 February 2019 / Accepted: 5 June 2019 /Published online: 27 August 2019

(C) Springer-Verlag GmbH Germany, part of Springer Nature 2019

\begin{abstract}
Health systems and governments are increasingly required to implement measures that target at-risk populations to prevent noncommunicable diseases. In this review we lay out what governments should be doing to prevent diabetes throughout the life course. The following four target groups were used to structure the specific recommendations: (1) pregnant women and young families, (2) children and adolescents, (3) working age population, and (4) the elderly. The evidence to date supports the effectiveness of some known government policy measures, such as sugar taxes and regulatory measures in the (pre-)school setting for children and adolescents. Many of these appear to be more effective if they are part of a bundle of strategies and if they are supplemented by communication strategies. Although there is a current focus on strategies that target the individual, governments can make use of evidence-based population-level prevention strategies. More research and continuous evaluation of the overall and subgroup-specific effectiveness of policy strategies using high-quality longitudinal studies are needed.
\end{abstract}

Keywords Communication strategy $\cdot$ Diabetes prevention $\cdot$ Life course development $\cdot$ Policy $\cdot$ Review

\begin{abstract}
Abbreviations
CVD Cardiovascular disease

GDM Gestational diabetes mellitus

SSB Sugar-sweetened beverage
\end{abstract}

\section{Introduction}

Diabetes affects more than 425 million people worldwide [1], and although one-third of the diabetic population is older than 65 years, an increasing proportion of children and adolescents [2] are suffering from this 'global societal catastrophe' [1]. Many adolescents with severe (morbid) obesity already show significant cardiometabolic sequelae, such as disturbed glucose tolerance and diabetes mellitus, arterial hypertension, dyslipidaemia and non-alcoholic fatty liver disease (NASH) [3]. As the risk of diabetes and associated complications increases with age [4], measures to prevent obesity and diabetes need to be implemented from early in life. Because of the approximately 10 15 years of slow and hidden progression of type 2 diabetes, many patients are unaware of their risk for developing
Electronic supplementary material The online version of this article (https://doi.org/10.1007/s00125-019-4941-y) contains peer-reviewed but unedited supplementary material, which is available to authorised users.

Patrick Timpel

patrick.timpel@tu-dresden.de

1 Department for Prevention and Care of Diabetes, Department of Medicine III, Faculty of Medicine Carl Gustav Carus, Technische Universität Dresden, Fetscherstraße 74, 01307 Dresden, Germany

2 Research Association Public Health Saxony/Center for Evidence-Based Healthcare, Faculty of Medicine Carl Gustav Carus, Technische Universität Dresden, Dresden, Germany
3 Department of Media and Communication Science, University of Erfurt, Erfurt, Germany

4 Department of Pediatrics I, Pediatric Endocrinology and Diabetology, Martin-Luther-University Halle-Wittenberg, Halle, Germany

5 Paul Langerhans Institute Dresden of the Helmholtz Center Munich at University Hospital and Faculty of Medicine, Technische Universität Dresden, Dresden, Germany

6 German Center for Diabetes Research (DZD), Munich, Neuherberg, Germany 
diabetes, or of the fact they already have type 2 diabetes $[5,6]$.

Although there are examples of effective policy initiatives to reduce cardiovascular diseases (CVD), for example, strategies to reduce smoking rates [7], there have been no policy initiatives to date that have successfully reduced the proportion of people at risk for diabetes which continues to rise as a result of obesity, unhealthy diet and limited physical activity [8].

In the past, landmark trials such as the UK Prospective Diabetes Study (UKPDS) [9], the Action to Control Cardiovascular Risk in Diabetes (ACCORD) study [10], the Action in Diabetes and Vascular Disease: Preterax and Diamicron MR Controlled Evaluation (ADVANCE) trial [11] and the Veteran's Affairs Diabetes Trial (VADT) [12] have proven the clinical benefit of medical treatments for individuals with diabetes. Complex lifestyle interventions, mostly combining a healthy diet with an increase in physical activity, such as the Finnish Diabetes Prevention Study (DPS), have also been shown to be effective in preventing diabetes and reducing high blood glucose levels and dyslipidaemia [13].

Established guidelines, like the Organisation for Economic Co-operation and Development (OECD) health policy studies on CVD and diabetes [8], as well as evidence-based recommendations given by the European guidelines on CVD prevention in clinical practice [14], suggest a focus on the entire continuum of diabetes prevention, management and care. Population-based interventions are able to address broad groups of people (at risk) [15] to decrease the distribution of a risk factor by a small degree [16]. By shifting the responsibility from the individual to the population at risk, populationbased interventions aim to change the setting or context individuals live in. The ultimate aim is to minimise the overall percentage of those at risk [17]. This can be achieved via policies translated into governmental regulations [18]. A health policy can be defined as a 'plan of action to guide decisions and actions' [19] and usually consists of the three interconnected, and preferably repeated, progressing phases: development, implementation and evaluation. Policy evaluation is defined as 'assessment of how, and how well, the policy works in practice' [20]. Communication campaigns are one important part of policy initiatives as they, by definition, target a large proportion of a population with strategic measures to raise awareness and motivate behavioural change. Modalities of communication activities involve (digital) mass media as well as interpersonal communication [21].

Interventions for prevention of diabetes commonly include communication strategies to inform individuals about the risk and symptoms of the disease and to try to persuade them to eat more healthily, be more physically active, and actively manage their diabetes [22]. Framing (i.e. the way content is presented), targeted according to the health literacy and media use of the population, as well as visualisation or the use of narratives are evidence-based communication strategies [23]. Communication campaigns have proven effective in improving disease-specific health literacy [24], persuading high-risk populations to take part in screenings [25], increasing patients' physical activity levels [26], promoting a healthy diet [27] and improving social support for patients with diabetes [28]. When used to accompany policy initiatives, communication strategies can reduce resistance and improve overall acceptance of the initiatives $[29,30]$.

However, certain at-risk groups, such as children from ethnic minorities or those from families with low socio-economic status, are insufficiently reached by most programmes [31]. Therefore, two-pronged strategies combining interventions to target individual risk behaviour as well as population-wide risk groups should be used to guide future care and policy development [32]. However, the successful translation of health research into policy is hampered by heterogeneity in measures and definitions of its impact [33]. Furthermore, policy makers infrequently use systematic reviews to guide decision making, because many systematic reviews tend to focus on documenting methodological rigour, without providing recommendations on the design of policy initiatives $[34,35]$. Consequently, evidence-based recommendations for policy makers on how to prevent diabetes and associated risk factors in different age groups are still lacking.

In this review we look at what governments should be doing to prevent diabetes throughout the life course. Specifically, we summarise evidence on effective strategies to prevent diabetes in the following four cohorts: (1) pregnant women and young families, (2) children and adolescents ( $<15$ years), (3) workingage population (15-64 years), (4) the elderly (>64 years) [36]. We present findings of a critical analysis of the impact of policies (and economic approaches) using these cohorts as examples (ESM Table 1). Building on the findings of effective policy measures and identified age-specific information needs, we then provide an overview of evidence-based communication strategies (health campaigns, food labelling, etc.). In our recommendations we include the categories of the national strategy and policy to prevent type 2 diabetes as set out by the National Institute for Health and Care Excellence (NICE) [37] (presented as headings in Table 1).

\section{Pregnant women and young families}

The Finnish Gestational Diabetes Prevention Study (RADIEL) revealed that simple and easily conducted lifestyle interventions are able to reduce the incidence of gestational diabetes (GDM) by $39 \%$ in high-risk pregnant women [47]. Such interventions should be initiated early in pregnancy and continue throughout the pregnancy, as major short- and long-term health consequences for both the mother and the child are likely. 


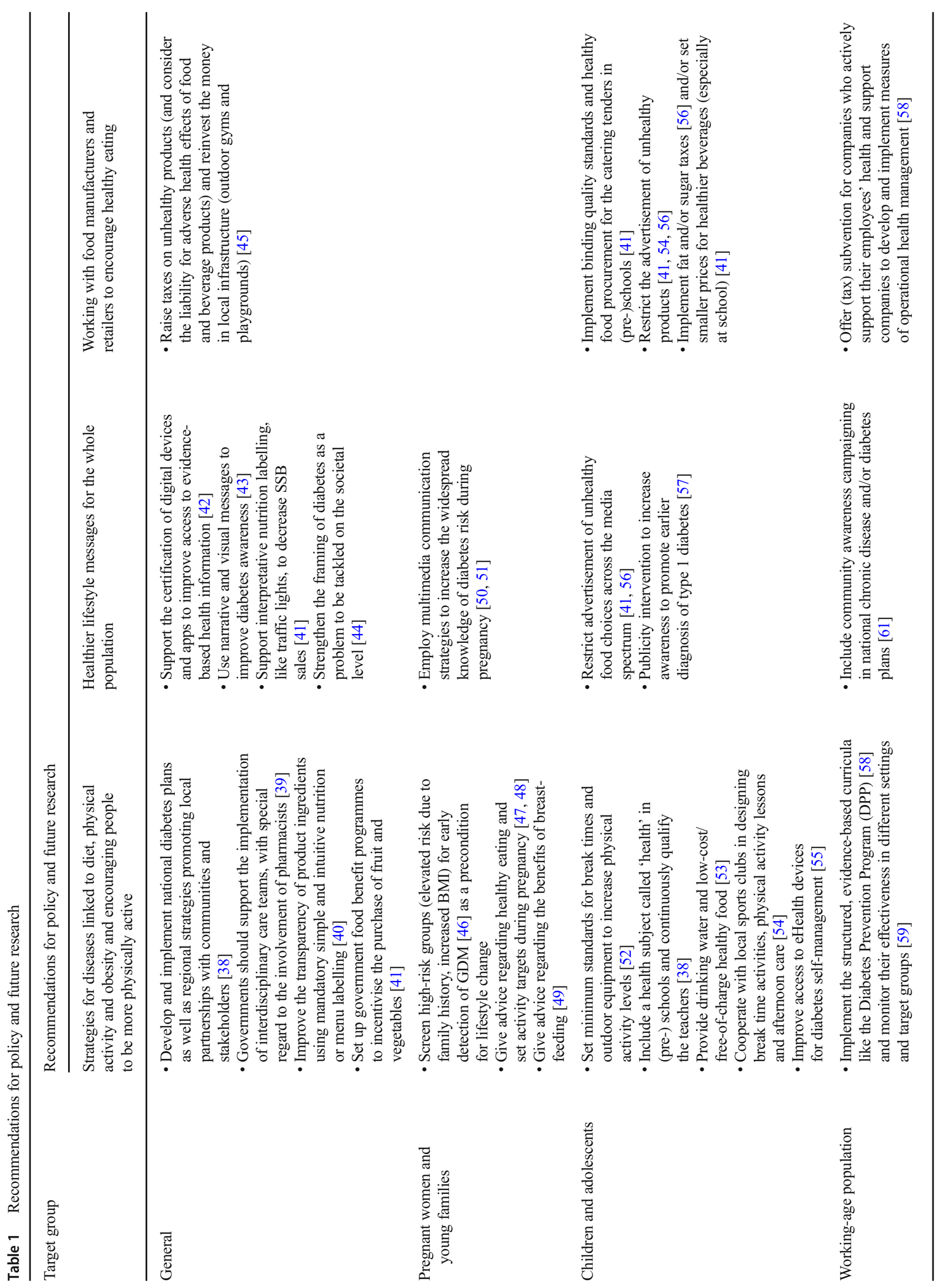




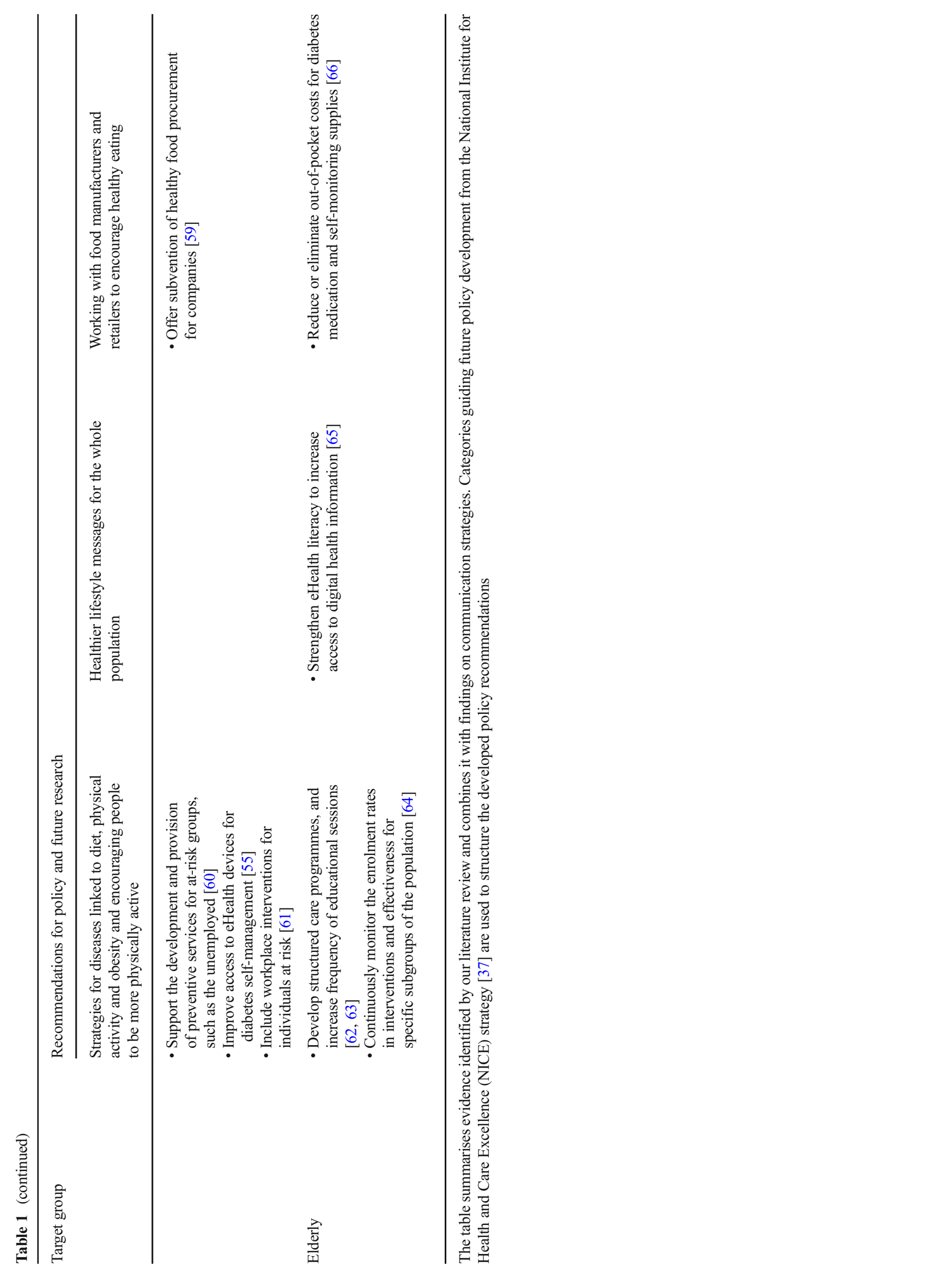


Interventions should, according to the authors, include regular counselling on dietary behaviour, such as the composition of a healthy meal (not more than $7530 \mathrm{~kJ}$ [1800 kcal] a day), and physical activity, before, during and after pregnancy [47]. Physical activity targets should be set in a way that they can be achieved easily, e.g. via household chores or active travel, and amount to no more than $30 \mathrm{~min}$ of moderate activity, five times a week [48]. Findings by Farrar and colleagues support the notion that accurately identifying women with GDM, as well as reducing costs of their identification and treatment, are relevant policy aims [46]. However, their meta-analysis-based economic evaluation revealed that it is not cost-effective to screen pregnant women routinely for hyperglycaemia, considering the UK national standard cost-effectiveness threshold of $£ 20,000$ per quality-adjusted life year (QALY). Therefore, they emphasise the importance of risk factor screening, i.e. screening of maternal characteristics, as this can be easily integrated into state-of-the-art antenatal care. In summary, easily accessible, structured and more authoritative population-based strategies have the potential to improve uptake of screening.

Pregnant women and young families should also be informed about the positive and protective long-term effects of breastfeeding, as there is strong and consistent evidence from the EarlyNutrition study that it prevents diabetes and comorbidities during the early years [49]. However, Martin and colleagues identified significant shortcomings in the compliance with WHO infant feeding recommendations. The authors also identified a gap in research regarding the composition of an ideal diet complementary to breastfeeding at 6 months [67], which, once determined, could be advocated by policy initiatives. Kamali and colleagues identified the information needs of pregnant women which should be met by government information strategies: infant feeding in general and newborn/ postpartum care rank high among these needs, as does exercise during pregnancy [50]. In general, governments should support the development, maintenance and regular monitoring of educational programmes for pregnant women.

\section{Children and adolescents}

Strategies for obesity prevention for children and adolescents have, to date, mainly focused on behavioural interventions. However, effect sizes have been only marginal [31]. One systematic review of the impact of school food environment policies on dietary habits, adiposity and metabolic risk in children [68], in which 91 interventions were analysed, reported that direct policies for providing healthy food in schools increased fruit and vegetable intake, whereas competitive food/beverage standards (such as productspecific restrictions; standards on nutrients, energy content, or portion sizes; or both) reduced consumption of sugarsweetened beverages (SSBs) and unhealthy snacks. In addition, school meal standards increased fruit intake and reduced total fat and saturated fat intake [68]. A recent Cochrane systematic review found existing effective and scalable interventions to reduce SSB consumption on a population-based level. Moderate certainty evidence was found for interpretative nutrition labelling (traffic lights), economic tools (price increases on SSBs), multicomponent community campaigns, and home-based interventions (home deliveries of diet beverages and bottled water) [41]. Another systematic review revealed that school district SSB policies and school food and nutrition policies can be effective in changing dietary habits [53]. However, approaches to increase physical activity or reduce sedentary behaviour within schools should address the multiple layers of the school environment (including activity settings within schools, teaching behaviours promoting physical activity), as they shape physical activity behaviours of children [52]. In addition, the period between a policy exposure and a change in a specific outcome measure needs to be considered carefully [53]. To date, studies involving young people in school- and community-based noncommunicable disease prevention interventions are scarce [69]. Furthermore, most analyses either report weak overall study quality $[53,70]$ or call for more rigorously carried out studies with longer follow-up periods $[38,71]$. Although data on the sustainability of school policies are lacking [53], policy debates can already make use of effective policies targeting food in the school environment as these have the potential to improve childhood dietary habits and health [68]. However, the lack of high-quality studies should be addressed by setting up specific funding programmes to adequately finance well-designed studies evaluating the impact of environmental interventions targeting children.

Taxes on SSBs have been shown to have a significant effect on the number of SSBs consumed per week by children from low-income families [56]. Governments should therefore consider the effects of policy measures relative to certain age groups as well as income groups.

Publicity interventions to increase awareness among healthcare professionals and the public have been shown to be effective at promoting the earlier diagnosis of type 1 diabetes in children and young people. One systematic review found evidence for the success of components such as provision of capillary blood-testing meters to healthcare professionals and diabetes educators, as well as posters and leaflets to reduce the rate of diabetes ketoacidosis [57]. Government strategies should therefore focus not solely on the population at risk, but on informing and enabling healthcare providers to accurately identify those at risk.

While digital devices can improve diabetes selfmanagement of adolescents [72, 73], especially when using social network functions, digitisation also holds risks for those target groups. An Australian analysis of digital marketing found evidence that mobile phone applications, brand 
websites and Facebook were being targeted by food and beverage companies to strategically advertise unhealthy food and beverages to children and adolescents [56]. Frequent use of flashing animations and music were used to attract attention [56]. Identifying and restricting these new ways to promote unhealthy dietary habits in the young should be of high priority when developing policy measures.

\section{Working-age populations}

Although digital technology has produced promising outcomes in terms of diabetes self-management even for patients of working age [74], less motivated adults might be better reached via interventions aiming at the setting they live in, i.e. their workplace or local community $[75,76]$. Here, behavioural-, financial- and communication-based strategies can be combined. Evidence synthesis indicates that the effectiveness of workplace interventions aiming to prevent type 2 diabetes can be increased by using the structured, evidence-based Diabetes Prevention Program (DPP) curriculum with only minor modifications [58]. However, obesity prevention studies in worksite-based interventions are scarce and the success of such programmes has been mixed [77]. By supporting guidelines for workplace-based interventions, governments may contribute to an improved evidence base in this setting.

A study on the effectiveness of workplace interventions for working age women in high-income countries reported that, although many cardiometabolic variables, including BMI, LDL-cholesterol and blood glucose, improved significantly, waist circumference, total cholesterol, HDLcholesterol, triacylglycerols and systolic blood pressure did not [78]. Analysing data from 14,272 patients derived from 17 studies, Shrestha and colleagues found significant pooled changes in $\mathrm{HbA}_{1 \mathrm{c}}(-0.18 \%)$ and in fasting glucose $(-0.14 \mathrm{mmol} / \mathrm{l})$ following dietary interventions in worksite settings [59]. While both analyses again call for more robust randomised controlled trials to provide high-quality evidence, Shrestha et al argue that, as larger effect sizes were observed for women, intervention planners and policy makers should consider the possibility that men might need extra support to achieve comparable effects to those observed in women [59]. In addition to the need for more setting-specific evidence, researchers call for the improved dissemination of existing programmes and information on their benefits and implementation processes [59].

Despite the evident impact of workplace interventions, the Northern Finland Birth Cohort Study concluded that policy strategies may consider screening for diabetes in middle-aged individuals independent of their work status, as unemployment was found to be related to impaired glucose metabolism and type 2 diabetes in men [60]. Based on the association between unemployment and type 2 diabetes in men, governments should consider developing health information appropriate to the level of health literacy of this subgroup of the population and consider new ways of disseminating this information.

\section{The elderly}

Structured care programmes, such as disease-management programmes for individuals with chronic diseases, aim to decrease mortality rates, reduce morbidity (e.g. diseasespecific complication rates), and to improve the general care process and overall quality of life. A systematic review evaluating the effectiveness of disease-management programmes in Germany uncovered benefits in terms of mortality rates, survival time and process parameters (such as doctor-patient relationships, and participation rates in diabetes education) [62]. In addition to improved care coordination, education in the form of training courses is still a promising way of receiving self-care information much needed to cope with the daily burden of disease [63]. However, the frequency of educational sessions for patients with diabetes remains unsatisfactory. Increasing awareness of the benefits of repeatedly participating in educational sessions, e.g. by increasing the availability of evidence-based health information (on websites or government-authorised health applications, etc.) are valuable strategies to increase the uptake of diabetes education.

A meta-analysis on the factors associated with medication engagement in older adults ( $\geq 60$ years) revealed that women (OR 0.92; 95\% CI 0.86, 0.97), patients with comorbid depression (OR $0.73 ; 95 \%$ CI 0.62, 0.87) and patients with increased out-of-pocket spending for prescribed drugs (OR 0.87; 95\% CI 0.80, 0.94) were less likely to take diabetes medication compared with the subgroups of men, patients without depression, and those with minor out-of-pocket costs, respectively [79]. Gourzoulidis and colleagues reported that spending on healthcare and medication play an important role for chronic disease management, as low copayment rates may increase medication adherence [80]. Another study found that each US\$5 increase in patient cost share (defined as the binding financial proportion patients have to incur when utilising health services) resulted in a $15 \%$ decrease in the adjusted odds of being adherent and a 0.1 percentage point increase in $\mathrm{HbA}_{1 \mathrm{c}}$ [81]. Again, these findings underline that there are multiple factors influencing adherence and health outcomes, which should be taken into account by governments when developing policies. Therefore, governments need to reflect carefully whether increasing copayments may have unintended economic effects outweighing the initial savings, e.g. by increased hospitalisation rates and outpatient visits after interruptions in treatment [80]. 


\section{Evidence-based communication strategies}

Targeting risk factors for diabetes and diabetes-related complications is one cornerstone of health policies, the other is using measures to provide information about the disease, its symptoms, risk factors and adequate preventive measures in evidence-based communication strategies [82]. Undiagnosed individuals or people not aware of their elevated risk in particular tend to have an information deficit, because they usually do not actively seek diabetes-related information [83]. In addition, a low social status, among other factors, negatively affects health literacy and, therefore, the ability to understand and apply health information [84]. The guideline for evidencebased health information developed by the German Network for Evidence-based Medicine lists several strategies (such as the use of pictures, narratives, exemplars) to increase the understandability of risk information [43]. For example, simple and intuitive nutrition or menu labelling (e.g. in grocery stores or restaurants) is promising, especially if pilot experiments involving target populations are used to guide policy implementation [85] and if the measures are part of a broader range of interventions [86]. Interventions used for diabetes prevention, for example, food labelling and tax exemption for healthy products can be combined with policies fixing the liability for adverse health effects of food and beverage products for the manufacturers [87].

Apart from the presentation of health information, the channel through which information is delivered also has to be audience specific. For many individuals, particularly the elderly, physicians are still the primary source of health information and, thus, valid gatekeepers for diabetes-related information and the promotion of behavioural change [88]. Investigating family-based diabetes interventions for adults, a systematic review found evidence for improvement in patients' self-efficacy, perceived social support, diabetes knowledge and diabetes self-care [89]. Informing family members living in the same household about possible complications such as hypoglycaemia can also improve emergency diabetes care $[90,91]$. Policy strategies to change diabetes-related and diabetes risk behaviour should therefore target not only the individual but also their direct social environment [45]. To enhance diabetes awareness both in the general population and in at-risk groups (e.g. individuals with impaired glucose tolerance or those with low literacy), governments should employ communication strategies based on targeting, the use of multiple media channels [42] and the involvement of an individual's support network, such as family and friends, as well as physicians [92-95]. Government strategies aiming to decrease the prevalence of risk factors for GDM should employ a broad spectrum of media channels to increase awareness rather than relying solely on the effectiveness of prepregnancy care [50, 51]. Accordingly, mass media channels, especially the internet, as well as workshops and symposia accessible to the public are valid sources of information for this group of rather active diabetes information seekers [50]. One systematic review found that older adults and adolescents alike prefer online media as their source for information on diabetes, although patients with diabetes wanted the online information to be verified by their medical expert (e.g. GP or dietitians) [96]. Not all elderly people have the necessary skills to use digital technologies. To prevent a digital divide in health literacy, governments should aim to increase eHealth literacy (i.e. skills to use digital health technologies [65]) and should still consider healthcare professionals as valid distributors of diabetes-related information.

Measures affecting whole population groups rather than just individuals at risk can trigger a negative reaction in those not affected by diabetes or those at risk. Therefore, it can also be necessary to increase public support for policy solutions by using both individual and societal-level framing of diabetes in government press releases [44]. Fittingly, the current Lancet Commission report on the global syndemic of obesity and undernutrition calls for comprehensive policy actions including communication activities in order to tackle the complex sequelae of malnutrition as well as the common underlying societal drivers they share [97].

\section{Policy implications}

In this review we have presented findings on the evaluation of the effectiveness and implementation of population-based strategies to prevent diabetes throughout the life course. Policy actions and population-based interventions help to increase the availability and quality of care and support healthier choices [1]. In line with the definition of policy provided above, several plans of action were presented which varied in refinement: Suggestions on how to develop new policy strategies were presented as well as drivers and barriers for the successful implementation of existing strategies. Finally, results from the evaluation of previous policy measures were reported.

Raising awareness of the risk of developing type 2 diabetes [98] and early diagnosis are seen as the major strategies to prevent and detect diabetes [61]. Although government-led awareness-raising communication campaigns have proven successful (e.g. in reducing smoking behaviour in adolescents [99]), evidence regarding diabetes prevention and detection is scarce. To overcome existing health inequalities in terms of vulnerable target groups of low health literacy and/or socioeconomic status, proportionate universalism is considered a key strategy for the development and implementation of health actions. This means that, as revealed by the Marmot Review, the scale and intensity of universal health actions should be proportionate to the level of disadvantage and need [100]. 
Policy strategies for preventing diabetes onset in early childhood do exist. The results presented here are in line with the Global Action Plan for the prevention and control of noncommunicable diseases of the WHO, which has suggested four measures to stop the obesity epidemic, aiming at the community setting rather than the individual. These measures include (1) restricting the advertisement of unhealthy foods to children, (2) improving school meals by developing binding quality standards for the catering offers in pre-schools and schools, (3) implementing a sugar or fat tax to reduce consumption of unhealthy foods, and (4) increasing daily physical activity by offering more physical activity/sports in schools and pre-schools [54]. Socalled 'fat taxes', as fiscal policy instruments, appear promising in reducing overall consumption of unhealthy food and beverages. However, their implementation is accompanied by widespread criticism from diverse stakeholders [8]. To improve the implementation of these measures, some researchers call for partnerships between policy makers and communities, helping to overcome districtspecific barriers, and recommend the implementation of nutrition education in US school grades kindergarten to twelfth grade (i.e. from approximately 5 to 19 years of age) [38]. Implementation is also unsatisfactory for workplace interventions for individuals at risk, despite the promising evidence presented for interventions targeting populations of working age. For example, there is no workplace intervention that has been incorporated into national diabetes plans in Europe [61].

As regards coordinated care programmes, the German disease-management programmes were implemented as policy initiatives 15 years ago and showed promising results in several evaluations [62, 64]. However, an analysis recently revealed that characteristics such as male sex, increased age and receiving a pension were associated with higher odds for enrolment in these programmes [101]. For policy makers, this is important on two counts: on the one hand, these results show that the effectiveness of structured care programmes may differ between certain subpopulations, on the other hand, they highlight a need to ensure equal odds for the enrolment of different groups.

On the health system level, two key health system obstacles to effective type 2 diabetes care and management have been identified, namely, financial barriers for the patient and limited access to health services and medication [66]. Health system factors may facilitate effective type 2 diabetes care and management, including (1) the use of innovative care models, (2) increased pharmacist involvement in care delivery, and (3) education programmes led by healthcare professionals [66]. Despite considerable heterogeneity between the primary studies included in the analysis [66], the potential of pharmacistled interventions is supported by findings by de Barra and colleagues [102]. Therefore, governments should support the implementation of interdisciplinary care teams, with special regard to the involvement of pharmacists [39].

For elderly patients, the cost of diabetes care, and medication in particular, can become a critical factor. Policy strategies should, therefore, aim to reduce or eliminate out-of-pocket costs for diabetes medication and self-monitoring supplies [66].

Finally, with special regard to demographic challenges and shortage of services, the EU commission anticipates there will be a need for policy strategies in digital health services such as telediagnosing [55], (i.e. diagnosing patients using information and communication technologies from a distance) [103]. This also includes the certification and payment of digital (prevention) services by public institutions and insurance companies. Accordingly, more evidence is needed on the optimal use of technology for patients with low health or eHealth literacy [104].

The International Diabetes Federation (IDF) summarises the following four recommendations to prevent diabetes locally, regionally and globally: (1) supporting accurate diabetes estimates by promoting high-quality research on diabetes epidemiology, (2) prioritising diabetes care and control by improving primary care and strengthening interdisciplinary collaboration, (3) implementing national diabetes plans and programmes, and (4) reducing diabetes and its complications by extending health promotion [1].

Unfortunately, although there is a need for populationbased approaches, their development is hampered by a lack of high-quality evidence on their effectiveness. This lack is due to methodological and economic reasons [39], as well as complex interrelationships between sociology, politics and economics and an individual's unique experiences of these interacting systems [105]. Most current analyses either call for more globalised actions or a stronger focus on implementation strategies [106]. However, Table 1 summarises evidence-based implications for governments guiding joint efforts to prevent diabetes throughout the life course, based on our literature search.

\section{Conclusion}

A range of policy strategies, which are available for governments to prevent diabetes throughout the life course, was identified. The findings underline the benefits of evidence-based policies, making use of direct investments in preventive services and effective target-group-specific communication strategies. In addition, digitisation holds great potential to intuitively reach out to those risk groups currently insufficiently targeted by established strategies. However, this potential is accompanied by new demands for governmental policies, e.g. in terms of supporting evidence-based online health information or the restriction of marketing for unhealthy products 
strategically targeting children. The identified evidence underlines that most policies can increase overall effectiveness if they are included within a broader strategy, including targeted high-risk and population-based measures, diabetes plans or community-based initiatives with local stakeholders. More research and continuous evaluation of policy strategies using high-quality longitudinal studies are needed.

Funding This research received no specific grant from any funding agency in the public, commercial or not-for-profit sectors.

Duality of interest The authors declare that there is no duality of interest associated with this manuscript.

Contribution statement All authors were responsible for drafting the article and revising it critically for important intellectual content. All authors approved the version to be published.

\section{References}

1. International Diabetes Federation (2017) IDF Diabetes Atlas, 8th edn. International Diabetes Federation, Brussels, Belgium

2. The Emerging Risk Factors Collaboration (2010) Diabetes mellitus, fasting blood glucose concentration, and risk of vascular disease: a collaborative meta-analysis of 102 prospective studies. Lancet 375(9733):2215-2222. https://doi.org/10.1016/S01406736(10)60484-9

3. The GBD 2015 Obesity Collaborators (2017) Health effects of overweight and obesity in 195 countries over 25 years. N Engl J Med 377(1):13-27. https://doi.org/10.1056/NEJMoa1614362

4. Huang ES, Laiteerapong N, Liu JY, John PM, Moffet HH, Karter AJ (2014) Rates of complications and mortality in older patients with diabetes mellitus: the diabetes and aging study. Complications in elderly diabetes patients. JAMA Intern Med 174(2):251-258. https://doi.org/10.1001/jamainternmed.2013. 12956

5. Mason CC, Hanson RL, Knowler WC (2007) Progression to type 2 diabetes characterized by moderate then rapid glucose increases. Diabetes 56(8):2054-2061. https://doi.org/10.2337/db07-0053

6. Ferrannini E, Nannipieri M, Williams K, Gonzales C, Haffner SM, Stern MP (2004) Mode of onset of type 2 diabetes from normal or impaired glucose tolerance. Diabetes 53(1):160-165. https://doi. org/10.2337/diabetes.53.1.160

7. Feliu A, Filippidis FT, Joossens L et al (2019) Impact of tobacco control policies on smoking prevalence and quit ratios in 27 European Union countries from 2006 to 2014. Tob Control 28(1):101. https://doi.org/10.1136/tobaccocontrol-2017-054119

8. OECD (2015) Cardiovascular disease and diabetes: policies for better health and quality of care. OECD Publishing, Paris. https://doi.org/10.1787/9789264233010-en

9. UK Prospective Diabetes Study (UKPDS) Group (1998) Intensive blood-glucose control with sulphonylureas or insulin compared with conventional treatment and risk of complications in patients with type 2 diabetes (UKPDS 33). Lancet 352(9131):837-853

10. Action to Control Cardiovascular Risk in Diabetes Study Group (2008) Effects of intensive glucose lowering in type 2 diabetes. N Engl J Med 358(24):2545-2559. https://doi.org/10.1056/ NEJMoa0802743

11. Group AC, Patel A, Macmahon S et al (2008) Intensive blood glucose control and vascular outcomes in patients with type 2 diabetes. N Engl J Med 358(24):2560-2572. https://doi.org/10. 1056/NEJMoa0802987

12. Duckworth W, Abraira C, Moritz T et al (2009) Glucose control and vascular complications in veterans with type 2 diabetes. $\mathrm{N}$ Eng1 J Med 360(2):129-139. https://doi.org/10.1056/ NEJMoa0808431

13. Tuomilehto J, Lindstrom J, Eriksson JG et al (2001) Prevention of type 2 diabetes mellitus by changes in lifestyle among subjects with impaired glucose tolerance. N Engl J Med 344(18):13431350. https://doi.org/10.1056/NEJM200105033441801

14. Piepoli MF, Hoes AW, Agewall S et al (2016) 2016 European guidelines on cardiovascular disease prevention in clinical practice: the Sixth Joint Task Force of the European Society of Cardiology and Other Societies on Cardiovascular Disease Prevention in Clinical Practice (constituted by representatives of 10 societies and by invited experts) developed with the special contribution of the European Association for Cardiovascular Prevention \& Rehabilitation (EACPR). Eur Heart J 37(29): 2315-2381. https://doi.org/10.1093/eurheartj/ehw106

15. Worley CG, Mohrman SA, Nevitt JA (2011) Large group interventions: an empirical field study of their composition, process, and outcomes. J Appl Behav Sci 47(4):404 431. https://doi.org/ 10.1177/0021886311410837

16. Rose G (1985) Sick individuals and sick populations. Int J Epidemiol 14(1):32-38. https://doi.org/10.1093/ije/14.1.32

17. Rose G (1981) Strategy of prevention: lessons from cardiovascular disease. Br Med J (Clin Res Ed) 282(6279):1847-1851. https:// doi.org/10.1136/bmj.282.6279.1847

18. OECD (2018) OECD regulatory policy outlook 2018. OECD Publishing, Paris. https://doi.org/10.1787/9789264303072-en

19. Kirch W (2008) Encyclopedia of public health. Springer, New York. https://doi.org/10.1007/978-1-4020-5614-7

20. Last JM (2007) A dictionary of public health. Oxford University Press, Oxford; New York

21. Atkin CK (2001) Chapter 3: theory and principles of media health campaigns. In: Atkin RERCK (ed) Public communication campaigns. SAGE Publications, Inc., Thousand Oaks, California. https://doi.org/10.4135/9781452233260.n3

22. McGuire WJ (2001) Public communication campaigns. In: Atkin RERCK (ed) Chapter 2: input and output variables currently promising for constructing persuasive communications. SAGE Publications, Inc., Thousand Oaks, California

23. Lühnen J, Albrecht M, Hanßen K, Hildebrandt J, Steckelberg A (2015) Leitlinie evidenzbasierte Gesundheitsinformation: Einblick in die Methodik der Entwicklung und Implementierung. Z Evid Fortbild Qual Gesundhwes 109(2): 159-165. https://doi.org/10.1016/j.zefq.2015.03.004

24. Kowall B, Rathmann W, Stang A et al (2017) Perceived risk of diabetes seriously underestimates actual diabetes risk: the KORA FF4 study. PLoS One 12(1):e0171152. https://doi.org/10.1371/ journal.pone. 0171152

25. Kennedy MPT, Cheyne L, Darby M et al (2018) Lung cancer stage-shift following a symptom awareness campaign. Thorax 73(12):1128-1136. https://doi.org/10.1136/thoraxjnl-2018211842

26. Janssen E, Ruiter RAC, Waters EA (2018) Combining risk communication strategies to simultaneously convey the risks of four diseases associated with physical inactivity to sociodemographically diverse populations. J Behav Med 41(3):318332. https://doi.org/10.1007/s10865-017-9894-3

27. Rohani H, Bidkhori M, Eslami AA, Sadeghi E, Sadeghi A (2018) Psychological factors of healthful diet promotion among diabetics: an application of health action process approach. Electron Physician 10(4):6647-6654. https://doi.org/10.19082/6647

28. Turner JW, Tian Y, Neustadtl A, Mun SK, Levine B (2019) The relationship between emotional and esteem social support 
messages and health AU - Robinson, James D. Health Commun 34(2):220-226. https://doi.org/10.1080/10410236.2017.1405476

29. Calderón JL, Beltrán RA (2004) Pitfalls in health communication: healthcare policy, institution, structure, and process. Medscape Gen Med 6(1):9-9

30. World Health Organization (2017) WHO strategic communications framework for effective communications. WHO, Geneva, $\mathrm{p}$ 56

31. Ludwig J, Sanbonmatsu L, Gennetian L et al (2011) Neighborhoods, obesity, and diabetes-a randomized social experiment. N Engl J Med 365(16):1509-1519. https://doi.org/10. 1056/NEJMsa1103216

32. Martin GP, Kocman D, Stephens T, Peden CJ, Pearse RM (2017) Pathways to professionalism? Quality improvement, care pathways, and the interplay of standardisation and clinical autonomy. Sociol Health Illn 39(8):1314-1329. https://doi.org/10.1111/14679566.12585

33. Alla K, Hall WD, Whiteford HA, Head BW, Meurk CS (2017) How do we define the policy impact of public health research? A systematic review. Health Res Policy Syst 15(1):84-84. https:// doi.org/10.1186/s12961-017-0247-z

34. Laupacis A, Straus S (2007) Systematic reviews: time to address clinical and policy relevance as well as methodological rigor relevance and rigor of systematic reviews. Ann Intern Med 147(4): 273-274. https://doi.org/10.7326/0003-4819-147-4-20070821000180

35. Lavis JN, Posada FB, Haines A, Osei E (2004) Use of research to inform public policymaking. Lancet 364(9445):1615-1621. https://doi.org/10.1016/S0140-6736(04)17317-0

36. OECD (2018) OECD labour force statistics 2018. OECD Publishing, Paris

37. National Institute for Health and Care Excellence (2018) National strategy and policy to prevent type 2 diabetes. Available from https://pathways.nice.org.uk/pathways/preventing-type-2diabetes/national-strategy-and-policy-to-prevent-type-2-diabetes, accessed 5 Feb 2019

38. Mansfield JL, Savaiano DA (2017) Effect of school wellness policies and the Healthy, Hunger-Free Kids Act on food-consumption behaviors of students, 2006-2016: a systematic review. Nutr Rev 75(7):533-552. https://doi.org/10.1093/nutrit/nux020

39. Schwarz PEH, Timpel P, Harst L et al (2018) Blood sugar regulation for cardiovascular health promotion and disease prevention: JACC health promotion series. J Am Coll Cardiol 72(15):1829 1844. https://doi.org/10.1016/j.jacc.2018.07.081

40. Raine KD, Atkey K, Olstad DL et al (2018) Healthy food procurement and nutrition standards in public facilities: evidence synthesis and consensus policy recommendations. Health Promot Chronic Dis Prev Can 38(1):6-17. https://doi.org/10.24095/ hpcdp.38.1.03

41. von Philipsborn P, Stratil JM, Burns J et al (2019) Environmental interventions to reduce the consumption of sugar-sweetened beverages and their effects on health. Cochrane Database Syst Rev (6). https://doi.org/10.1002/14651858.CD012292.pub2

42. George KS, Roberts CB, Beasley S, Fox M, Rashied-Henry K (2016) Our health is in our hands: a social marketing campaign to combat obesity and diabetes. Am J Health Promot 30(4):283286. https://doi.org/10.1177/0890117116639559

43. Luehnen J, Albrecht M, Mühlhauser I, Steckelberg A (2017) Leitlinie evidenzbasierte Gesundheitsinformation. Hamburg. Available from https://www.leitlinie-gesundheitsinformation.de/ wp-content/uploads/2017/07/Leitlinie-evidenzbasierteGesundheitsinformation.pdf

44. Stefanik-Sidener K (2013) Nature, nurture, or that fast food hamburger: media framing of diabetes in the New York Times from 2000 to 2010. Health Commun 28(4):351-358. https://doi.org/10. $1080 / 10410236.2012 .688187$
45. Huffman JC, Celano CM, Malloy LM, Wexler DJ, Freedman ME, Millstein RA (2018) The role of spousal support for dietary adherence among type 2 diabetes patients: a narrative review AU Albanese, Ariana M. Social work in health care 1-20. https://doi. org/10.1080/00981389.2018.1563846

46. Farrar D, Simmonds M, Susan G et al (2016) The identification and treatment of women with hyperglycaemia in pregnancy: an analysis of individual participant data, systematic reviews, metaanalyses and an economic evaluation. Health Technol Assess 20(86):348-348. https://doi.org/10.3310/hta20860

47. Koivusalo SB, Rönö K, Klemetti MM et al (2016) Gestational diabetes mellitus can be prevented by lifestyle intervention: the Finnish Gestational Diabetes Prevention Study (RADIEL). Diabetes Care 39(1):24-30. https://doi.org/10.2337/dc15-0511

48. Rönö K, Stach-Lempinen B, Klemetti MM et al (2014) Prevention of gestational diabetes through lifestyle intervention: study design and methods of a Finnish randomized controlled multicenter trial (RADIEL). BMC Pregnancy Childbirth 14(1):70. https://doi.org/ 10.1186/1471-2393-14-70

49. Zalewski BM, Patro B, Veldhorst M et al (2017) Nutrition of infants and young children (one to three years) and its effect on later health: a systematic review of current recommendations (EarlyNutrition project). Crit Rev Food Sci Nutr 57(3):489-500. https://doi.org/10.1080/10408398.2014.888701

50. Kamali S, Ahmadian L, Khajouei R, Bahaadinbeigy K (2018) Health information needs of pregnant women: information sources, motives and barriers. Health Inf Libr J 35(1):24-37. https://doi.org/10.1111/hir.12200

51. Khooshehchin TE, Keshavarz Z, Afrakhteh M, Shakibazadeh E, Faghihzadeh S (2016) Perceived needs in women with gestational diabetes: a qualitative study. Electron Physician 8(12):3412-3420. https://doi.org/10.19082/3412

52. Morton KL, Atkin AJ, Corder K, Suhrcke M, van Sluijs EMF (2016) The school environment and adolescent physical activity and sedentary behaviour: a mixed-studies systematic review. Obes Rev 17(2):142-158. https://doi.org/10.1111/obr.12352

53. Singh A, Bassi S, Nazar GP et al (2017) Impact of school policies on non-communicable disease risk factors - a systematic review. BMC Public Health 17(1):292. https://doi.org/10.1186/s12889017-4201-3

54. Effertz T, Garlichs D, Gerlach S et al (2015) Wirkungsvolle Prävention chronischer Krankheiten: Strategiepapier der NCDAllianz zur Primärprävention. Präv Gesundheitsf 10(1):95-100. https://doi.org/10.1007/s11553-014-0483-9

55. Communication) ECD-Gf (2017) Weissbuch zur Zukunft Europas In: Die EU der 27 im Jahr 2025 - Überlegungen und Szenarien. Europäische Kommission, Brussels

56. Backholer K, Boelsen-Robinson T, Peeters A (2015) Digital marketing of unhealthy foods to Australian children and adolescents. Health Promot Int 31(3):523-533. https://doi.org/10.1093/heapro/ dav008

57. Deylami R, Townson J, Mann M, Gregory JW (2017) Systematic review of publicity interventions to increase awareness amongst healthcare professionals and the public to promote earlier diagnosis of type 1 diabetes in children and young people. Pediatr Diabetes 19(3):566-573. https://doi.org/10.1111/pedi.12565

58. Hafez D, Fedewa A, Moran M, O'Brien M, Ackermann R, Kullgren JT (2017) Workplace interventions to prevent type 2 diabetes mellitus: a narrative review. Curr Diab Rep 17(2):9-14. https://doi.org/10.1007/s11892-017-0840-0

59. Shrestha A, Karmacharya BM, Khudyakov P, Weber MB, Spiegelman D (2017) Dietary interventions to prevent and manage diabetes in worksite settings: a meta-analysis. J Occup Health 60(1):31-45. https://doi.org/10.1539/joh.17-0121-RA

60. Rautio N, Varanka-Ruuska T, Vaaramo E et al (2017) Accumulated exposure to unemployment is related to impaired 
glucose metabolism in middle-aged men: a follow-up of the Northern Finland Birth Cohort 1966. Prim Care Diabetes 11(4): 365-372. https://doi.org/10.1016/j.pcd.2017.03.010

61. Richardson E, Zaletel J, Nolte E, on behalf of Joint Action CHRODIS (2016) National Diabetes Plans in Europe: what lessons are there for the prevention and control of chronic diseases in Europe? In: Richardson E (ed) Policy brief, ISSN 1997-8065. National Institute of Public Health ; Copenhagen; World Health Organization, Regional Office for Europe, Ljubljana

62. Fuchs S, Henschke C, Blümel M, Busse R (2014) Disease management programs for type 2 diabetes in Germany: a systematic literature review evaluating effectiveness. Dtsch Arztebl Int 111(26):453-463. https://doi.org/10.3238/arztebl.2014.0453

63. Bergis-Jurgan N, Ehrmann D, Haak T, Kulzer B, Hermanns N (2014) Ambulante Schulung bei Typ-2-Diabetes. Diabetologe 10(4):293-299. https://doi.org/10.1007/s11428-013-1185-1

64. Mehring M, Donnachie E, Bonke FC, Werner C, Schneider A (2017) Disease management programs for patients with type 2 diabetes mellitus in Germany: a longitudinal population-based descriptive study. Diabetol Metab Syndr 9(1):37. https://doi.org/ 10.1186/s13098-017-0236-y

65. Cartmill B, Wall LR, Ward EC, Hill AJ, Porceddu SV (2016) Computer literacy and health locus of control as determinants for readiness and acceptability of telepractice in a head and neck cancer population. Int J Telerehabil 8(2):49-60. https://doi.org/10. 5195/ijt.2016.6203

66. Ong SE, Koh JJK, Toh S-AES et al (2018) Assessing the influence of health systems on type 2 diabetes mellitus awareness, treatment, adherence, and control: a systematic review. PLoS One 13(3): e0195086-e0195086. https://doi.org/10.1371/journal.pone. 0195086

67. Martin A, Bland RM, Connelly A, Reilly JJ (2016) Impact of adherence to $\mathrm{WHO}$ infant feeding recommendations on later risk of obesity and non-communicable diseases: systematic review. Matern Child Nutr 12(3):418-427. https://doi.org/10.1111/mcn. 12201

68. Micha R, Karageorgou D, Bakogianni I et al (2018) Effectiveness of school food environment policies on children's dietary behaviors: a systematic review and meta-analysis. PLoS One 13(3): e0194555. https://doi.org/10.1371/journal.pone.0194555

69. Jourdan D, Christensen JH, Darlington E et al (2016) The involvement of young people in school- and community-based noncommunicable disease prevention interventions: a scoping review of designs and outcomes. BMC Public Health 16(1):11231123. https://doi.org/10.1186/s12889-016-3779-1

70. Wolfenden L, Nathan NK, Sutherland R et al (2017) Strategies for enhancing the implementation of school-based policies or practices targeting risk factors for chronic disease. Cochrane Database Syst Rev (11). https://doi.org/10.1002/14651858.CD011677.pub2

71. Wolfenden L, Jones J, Williams CM et al (2016) Strategies to improve the implementation of healthy eating, physical activity and obesity prevention policies, practices or programmes within childcare services. Cochrane Database Syst Rev (10). https://doi. org/10.1002/14651858.CD011779.pub2

72. Goyal S, Nunn CA, Rotondi M et al (2017) A mobile app for the self-management of type 1 diabetes among adolescents: a randomized controlled trial. JMIR Mhealth Uhealth 5(6):e82. https://doi. org/10.2196/mhealth.7336

73. Martinez-Millana A, Jarones E, Fernandez-Llatas C, Hartvigsen G, Traver V (2018) App features for type 1 diabetes support and patient empowerment: systematic literature review and benchmark comparison. JMIR Mhealth Uhealth 6(11):e12237-e12237. https://doi.org/10.2196/12237

74. Fang R, Deng X (2018) Electronic messaging intervention for management of cardiovascular risk factors in type 2 diabetes mellitus: a randomised controlled trial. J Clin Nurs 27(3-4):612620. https://doi.org/10.1111/jocn.13962

75. Kent K, Goetzel RZ, Roemer EC, Prasad A, Freundlich N (2016) Promoting healthy workplaces by building cultures of health and applying strategic communications. J Occup Environ Med 58(2): 114-122. https://doi.org/10.1097/JOM.0000000000000629

76. Dadaczynski K, Baumgarten K, Hartmann T (2016) Settingbasierte Gesundheitsförderung und Prävention. Prävention und Gesundheitsförderung 11(4):214-221. https:// doi.org/10.1007/s11553-016-0562-1

77. Panter JC, Andersen PT, Aro AR, Samara A (2018) Obesity prevention: a systematic review of setting-based interventions from Nordic countries and the Netherlands. J Obes 2018:34-34. https:// doi.org/10.1155/2018/7093260

78. Reed JL, Prince SA, Elliott CG et al (2017) Impact of workplace physical activity interventions on physical activity and cardiometabolic health among working-age women. Circ Cardiovasc Qual Outcomes 10(2):e003516. https://doi.org/10.1161/ CIRCOUTCOMES.116.003516

79. Choi YJ, Smaldone AM (2017) Factors associated with medication engagement among older adults with diabetes: systematic review and meta-analysis. Diabetes Educ 44(1):15-30. https:// doi.org/10.1177/0145721717747880

80. Gourzoulidis G, Kourlaba G, Stafylas P, Giamouzis G, Parissis J, Maniadakis N (2017) Association between copayment, medication adherence and outcomes in the management of patients with diabetes and heart failure. Health Policy 121(4):363-377. https:// doi.org/10.1016/j.healthpol.2017.02.008

81. Hunt J, Rozenfeld Y, Shenolikar R (2009) Effect of patient medication cost share on adherence and glycemic control. Manag Care 18(7):47-53

82. Welschen LMC, Bot SDM, Kostense PJ et al (2012) Effects of cardiovascular disease risk communication for patients with type 2 diabetes on risk perception in a randomized controlled trial: the @ RISK study. Diabetes Care 35(12):2485-2492. https://doi.org/ $10.2337 / \mathrm{dc} 11-2130$

83. Kayyali R, Slater N, Sahi A, Mepani D, Lalji K, Abdallah A (2019) Type 2 diabetes: how informed are the general public? A cross-sectional study investigating disease awareness and barriers to communicating knowledge in high-risk populations in London. BMC Public Health 19(1):138. https://doi.org/10.1186/s12889019-6460-7

84. Rikard RV, Thompson MS, McKinney J, Beauchamp A (2016) Examining health literacy disparities in the United States: a third look at the National Assessment of Adult Literacy (NAAL). BMC Public Health 16(1):975. https://doi.org/10.1186/s12889-0163621-9

85. Liu PJ, Wisdom J, Roberto CA, Liu LJ, Ubel PA (2013) Using behavioral economics to design more effective food policies to address obesity. Appl Econ Perspect Policy 36(1):6-24. https:// doi.org/10.1093/aepp/ppt027

86. Crockett RA, King SE, Marteau TM et al (2018) Nutritional labelling for healthier food or non-alcoholic drink purchasing and consumption. Cochrane Database Syst Rev 2(2):CD009315CD009315. https://doi.org/10.1002/14651858.CD009315.pub2

87. Schwarz PEH, Riemenschneider H (2016) Slowing down the progression of type 2 diabetes: we need fair, innovative, and disruptive action on environmental and policy levels! Diabetes Care 39(Supplement 2):S121-S126. https://doi.org/10.2337/dcS153001

88. Baumann E, Czerwinski F (2015) Erst mal Doktor Google fragen? Nutzung Neuer Medien zur Information und zum Austausch über Gesundheitsthemen. In: J. Böcken BB, Meierjürgen R (eds) Gesundheitsmonitor 2015: Bürgerorientierung im Gesundheitswesen. Bertelsmann Stiftung., Gütersloh, pp 57-79 
89. Baig AA, Benitez A, Quinn MT, Burnet DL (2015) Family interventions to improve diabetes outcomes for adults. Ann N Y Acad Sci 1353(1):89-112. https://doi.org/10.1111/nyas.12844

90. Gunn KL, Seers K, Posner N, Coates V (2012) 'Somebody there to watch over you': the role of the family in everyday and emergency diabetes care. Health Soc Care Community 20(6):591-598. https://doi.org/10.1111/j.1365-2524.2012.01073.x

91. Reifegerste D, Hartleib S (2016) Hypoglycemia-related information seeking among informal caregivers of type 2 diabetes patients: implications for health education. J Clin Transl Endocrinol 4:7-12. https://doi.org/10.1016/j.jcte.2016.02.001

92. Wijayaratne SP, Reid M, Westberg K, Worsley A, Mavondo F (2018) Food literacy, healthy eating barriers and household diet. Eur J Mark 52(12):2449-2477. https://doi.org/10.1108/EJM-102017-0760

93. Strom JL, Egede LE (2012) The impact of social support on outcomes in adult patients with type 2 diabetes: a systematic review. Curr Diab Rep 12(6):769-781. https://doi.org/10.1007/s11892012-0317-0

94. August KJ, Rook KS, Franks MM, Parris Stephens MA (2013) Spouses' involvement in their partners' diabetes management: associations with spouse stress and perceived marital quality. J Fam Psychol 27(5):712-721. https://doi.org/10.1037/a0034181

95. Edwards M, Wood F, Davies M, Edwards A (2015) 'Distributed health literacy': longitudinal qualitative analysis of the roles of health literacy mediators and social networks of people living with a long-term health condition. Health Expect 18(5):1180-1193. https://doi.org/10.1111/hex.12093

96. Kuske S, Schiereck T, Grobosch S et al (2017) Diabetes-related information-seeking behaviour: a systematic review. Syst Rev 6(1):212. https://doi.org/10.1186/s13643-017-0602-8

97. Swinburn BA, Kraak VI, Allender S et al (2019) The global syndemic of obesity, undernutrition, and climate change: the Lancet Commission report. Lancet 393(10173):791-846. https:// doi.org/10.1016/S0140-6736(18)32822-8

98. Morton S, Kirkwood S, Thangaratinam S (2014) Interventions to modify the progression to type 2 diabetes mellitus in women with gestational diabetes: a systematic review of literature. Curr Opin
Obstet Gynecol 26(6):476-486. https://doi.org/10.1097/gco. 0000000000000127

99. Cowell AJ, Farrelly MC, Chou R, Vallone DM (2009) Assessing the impact of the national 'truth' antismoking campaign on beliefs, attitudes, and intent to smoke by race/ethnicity. Ethn Health 14(1): 75-91. https://doi.org/10.1080/13557850802257715

100. Marmot M, Atkinson T, Bell J, Black C, Broadfoot P, Cumberlege J (2017) Fair society, healthy lives: strategic review of health inequalities in England post-2010. The Marmot Review. 2010. London, Institute of Health Equity

101. Röttger J, Blümel M, Busse R (2017) Selective enrollment in disease management programs for coronary heart disease in Germany - an analysis based on cross-sectional survey and administrative claims data. BMC Health Serv Res 17(1):246-246. https://doi.org/10.1186/s12913-017-2162-y

102. de Barra M, Scott CL, Scott NW et al (2018) Pharmacist services for non-hospitalised patients. Cochrane Database Syst Rev (9). https://doi.org/10.1002/14651858.CD013102

103. Bashshur RL, Howell JD, Krupinski EA, Harms KM, Bashshur N, Doarn CR (2016) The empirical foundations of telemedicine interventions in primary care. Telemed J E Health 22(5):342-375. https://doi.org/10.1089/tmj.2016.0045

104. Parker SM, Stocks N, Nutbeam D et al (2018) Preventing chronic disease in patients with low health literacy using eHealth and teamwork in primary healthcare: protocol for a cluster randomised controlled trial. BMJ Open 8(6):e023239. https://doi.org/10.1136/ bmjopen-2018-023239

105. Ali MK, Wharam F, Kenrik Duru O et al (2018) Advancing health policy and program research in diabetes: findings from the natural experiments for translation in diabetes (NEXT-D) network. Curr Diab Rep 18(12):146. https://doi.org/10.1007/s11892-018-1112-3

106. Hu FB, Satija A, Manson JE (2015) Curbing the diabetes pandemic: the need for global policy solutions. JAMA 313(23):23192320. https://doi.org/10.1001/jama.2015.5287

Publisher's note Springer Nature remains neutral with regard to jurisdictional claims in published maps and institutional affiliations. 